\title{
MODELLING OF A NEARSHORE PLACED SAND MOUND
}

\section{Ernest R. Smith, Felice D’Alessandro, Giuseppe R. Tomasicchio, J oseph Z. Gailani}

Ernest.R.Smith@erdc.usace.army.mil - felice.dalessandro@unisalento.it - roberto.tomasicchio@unisalento.it - Joe.Z.Gailani@erdc.usace.army.mil

UNIVERSITÀ

DEL SALENTO

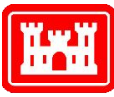

US Army Corps

of Engineers

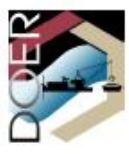

Dredging Operations and

Environmental Research
INTRODUCTION

Nearshore placement of sand is becoming a more popular option in two related types of coasta engineering projects: beach nourishment and inlet dredging. Placing the sand in the nearshore instead of directly on the beach can reduce the costs of a beach nourishment project (Douglass 1995); furthermore, the environmental impact to the beach and dune ecosystem may be perceived to be less for open-water disposal with subsequent migration than for direct placement on the beach. Nearshore placement of sand is also an option in navigation dredging projects for similar reasons.

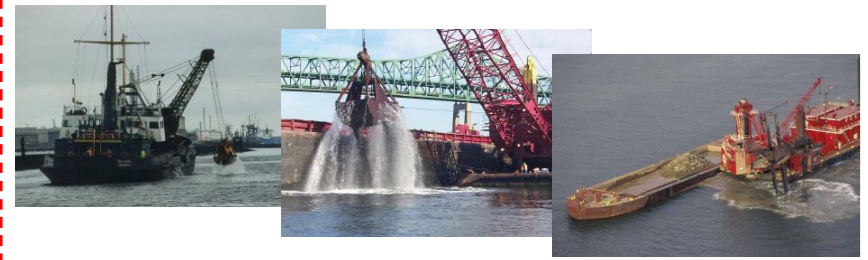

Several design and planning questions relate to the fate of dredged sand placed in the nearshore.

- Can we economically use profile nourishment, and what is the certainty that a constructed submerged feature will move onshore or remain in place?

- And if it will move, what is the rate of its movement? Another question concerns how deep material should be placed.

In order to answer these questions, together with physical model experiments, several empirical/numerical models have been developed in the past in the United States as a part of the Corps of Engineers ‘Dredging Research Program' (DRP) (Hands 1991, Larson and Kraus 1992).

Hydrodynamic modelling of the nearshore environment has reached a verifiable level of maturity in the last decades as a result of well-defined equations, established numerical solutions and quality laboratory and field data. On the contrary, modelling of sediment transport and beach profile evolution has not yet approached a similar level of accuracy. Most commonly applied models to predict beach profile modifications and to estimate the migration rate of nearshore constructed sand mounds rely on empirical relationships (Douglass 1995). More recently, the numerical model C-SHORE (Kobayashi et al. 2007; Figlus et al. 2011) was developed resulting in simple, practical and accurate code that predicts beach-dune profile evolution over the nearshore region in response to waves, currents and water levels.

In the present work, a calibration and verification procedure is considered for the numerical model C-SHORE (Kobayashi et al. 2007) and the empirical model (Douglass 1995).

\section{LABORATORY EXPERIMENTS}

Physical model experiments were conducted as a part of the U.S. Army Corps of Engineers 'Dredging Operations and Environmental Research' (DOER) program to study the migration and dispersion processes of a nearshore placed dredged mound subjected to waves and currents (Smith and Gailani 2005). The experiments were carried out at the Large-scale Sediment Transport Facility (LSTF) of the U.S. Army Engineer Research and Development Center's (ERDC) Coastal and Hydraulics Laboratory in Vicksburg, USA.

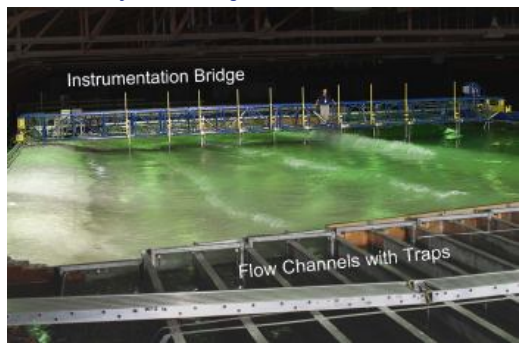

The LSTF is $30 \mathrm{~m}$ wide, $50 \mathrm{~m}$ long, and $14 \mathrm{~m}$ deep. Long-crested and unidirectional irregula waves having $H_{m 0}=0.16 \mathrm{~m}$ and $T_{p}=1,5 \mathrm{~s}$ were generated by four synchronized wave makers oriented at a 10-deg angle to the shoreline. The beach was composed of well-sorted fine quartz sand with a median grain size, $D_{50}$ of $0.15 \mathrm{~mm}$.

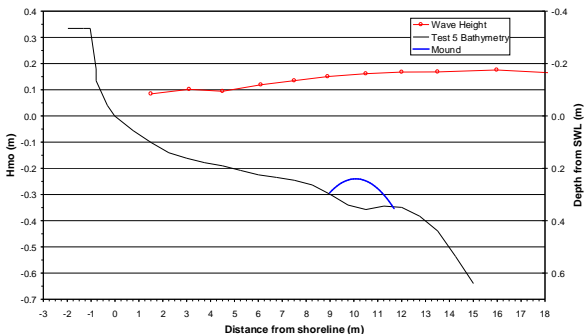

An external recirculation system minimized adverse physical model effects at the beach boundaries. Twenty $0.75-\mathrm{m}$ wide and 6 -m long bottom traps were used to measure the total longshore sediment flux. Time series of water surface elevations were measured using ten wave gauges mounted on the instrumentation bridge. Additionally a gauge was placed in front of each wave maker to determine the offshore wave characteristics. Ten ADVs were used to measure the velocity time series including steady longshore currents. The beach was surveyed with an acoustic profiler.

\section{NEARSHORE MOUND}

The mound was constructed to be representative of a nearshore dredged material placement. The mound had a parabolic shape with a $3 \mathrm{~m}$ diameter and $0.1 \mathrm{~m}$ height and was placed at the cross-shore location where a significant loss of wave energy occurs. The target cross-shore location for the mound centre was $x=12.7 \mathrm{~m}$, which placed the mound within the incipient breaking region and on the flat portion of the beach. The longshore location of the mound was determined by placing it in a region where waves and currents remain uniform near and downstream (migration direction) of the mound. Based on previous LSTF experiments, alongshore uniformity was maintained between locations $\mathrm{y}=18 \mathrm{~m}$ and $\mathrm{y}=30 \mathrm{~m}$ (Hamilton et al. $200 \mathrm{lb}$ ). The selected mound centre was chosen at $y=28 \mathrm{~m}$, which placed the mound near the upstream side of the uniform wave/current region.

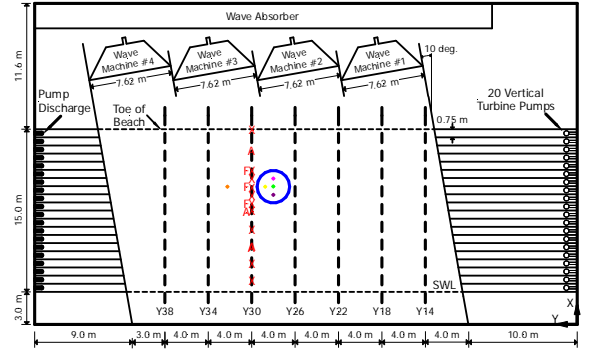

$X$ - Wave Gage - ADV par
$A-$ ADV

The mound was subjected to 10 hours of waves with interruptions to survey the nearshore beach. Surveys were taken at approximately $1,3,5,7.5$, and 10 hours. The profile at $y=28 \mathrm{~m}$ (the longshore location of the initial mound center) is shown in the figure below for each survey. The initial survey $(\mathrm{t}=0 \mathrm{~min})$ was taken prior to wave action on the beach. Subsequent surveys show ripples formed as a result of waves. Elevation of the mound decreased rapidly during the first hour, losing 17 percent of its original height. Elevation continued to decrease as the test progressed, but the rate of change was smaller. After 5 hours of testing the crest elevation was reduced by 50 percent and features of the initial mound disappeared. At the end of the experiment, the initial mound elevation at $y=28 \mathrm{~m}$ had decreased by 73 percent (Smith and Gailani 2005)
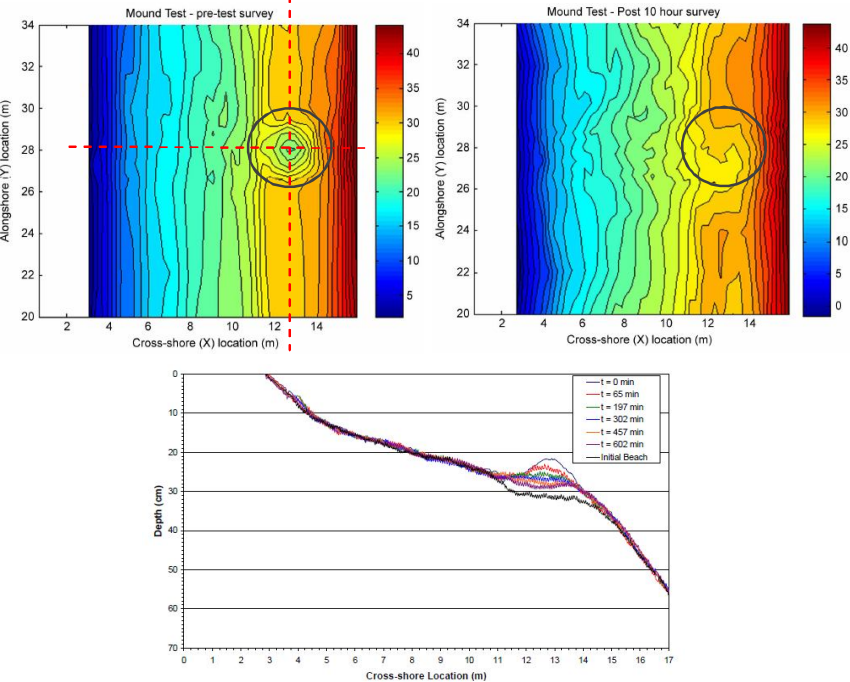

Mound evolution in time at $y=28 \mathrm{~m}$

\section{RESULTS}

The present work describes and discusses the migration and dispersion processes of the nearshore mound observed during the experiments. Furthermore the evolution in time of the beach profile with the placed mound is used to calibrate and validate the time-averaged numerical model C-SHORE (Kobayashi et al. 2007) based on the assumption of long-shore uniformity in accordance with Hamilton et al (2001b). At an initial stage of the investigation, the numerical model compares well with the laboratory data. In addition, the empirical model by Douglass (1995) is calibrated and verified to estimate the expected onshore migration rate and to evaluate the influence of the water depth on the migration rate. The work, based on the comparison of laboratory observations and results from numerical and empirical models, intends to arrive to general recommendations and guidance for nearshore mound placement.

\section{ACKNOWLEDGMENTS}

The present study has been supported by the U.S. Army Corps of Engineers within the 'Dredging Operations and Environmental Research' (DOER) program: 